\title{
EFFECT OF AFT ROTOR ON THE INTER-ROTOR FLOW OF AN OPEN ROTOR PROPULSION SYSTEM
}

\author{
Paul E. Slaboch \\ Saint Martin's University \\ Lacey, WA, USA
}

\author{
David B. Stephens and Dale E. Van Zante \\ NASA Glenn Research Center \\ Cleveland, $\mathrm{OH}, \mathrm{USA}$
}

\begin{abstract}
The effects of the aft rotor on the inter-rotor flow field of an open rotor propulsion rig were examined. A Particle Image Velocimetry (PIV) dataset that was acquired phase locked to the front rotor position has been phase averaged based on the relative phase angle between the forward and aft rotors. The aft rotor phase was determined by feature tracking in raw PIV images through an image processing algorithm. The effects of the aft rotor potential field on the inter-rotor flow were analyzed and shown to be in reasonably good agreement with Computational Fluid Dynamics (CFD) simulations. The aft rotor position was shown to have a significant upstream effect, with implications for front rotor interaction noise. It was found that the aft rotor had no substantial effect on the position of the forward rotor tip vortex but did have a small effect on the circulation strength of the vortex when the rotors were highly loaded.
\end{abstract}

\section{NOMENCLATURE}

$U_{W} \quad$ Axial Velocity

$U_{R} \quad$ Radial Velocity

$U_{\Theta} \quad$ Tangential Velocity

$U_{M} \quad$ Velocity Magnitude, $\sqrt{ }\left(U_{W}{ }^{2}+U_{R}^{2}+U_{\Theta}{ }^{2}\right) / V_{l, t i p}$

$V_{l, t i p} \quad$ Front rotor tip speed

$R_{l} \quad$ Front Rotor Radius

$\phi \quad$ Aft Rotor Phase Angle

$\Gamma \quad$ Circulation

$\gamma \quad$ Circulation Density

\section{INTRODUCTION}

The rising cost of jet fuel along with other environmental These systems, also known as propfans or advanced propellers, were studied in the late 1970s and 1980s for their fuel efficiency benefits [1]. The majority of the fuel efficiency benefit comes from the high propulsive efficiency of these systems, typically at or above 0.95 relative to adiabatic efficiency. The open rotor propulsion systems also typically carry fan pressure ratios less concerns has renewed interest in open rotor propulsion systems.

than 1.3 and usually under 1.1 which gives significant efficiency benefits not only at cruise but also at lower flight speeds [2].

In the summer of 2010, the NASA Environmentally Responsible Aviation (ERA) project supported the collection of a large stereoscopic PIV dataset of the Open Rotor Propulsion Rig (ORPR) in the 9- $x$ 15-Foot Low Speed Wind Tunnel (9x15 LSWT) at the NASA Glenn Research Center (GRC). The rig operated with 12 front blades and 10 aft blades. A photo of the ORPR in the wind tunnel at GRC is shown in Figure 1. An overview of the ORPR wind tunnel test campaign and how it fits in the larger picture of progress on open rotor propulsion systems can be found in [2].

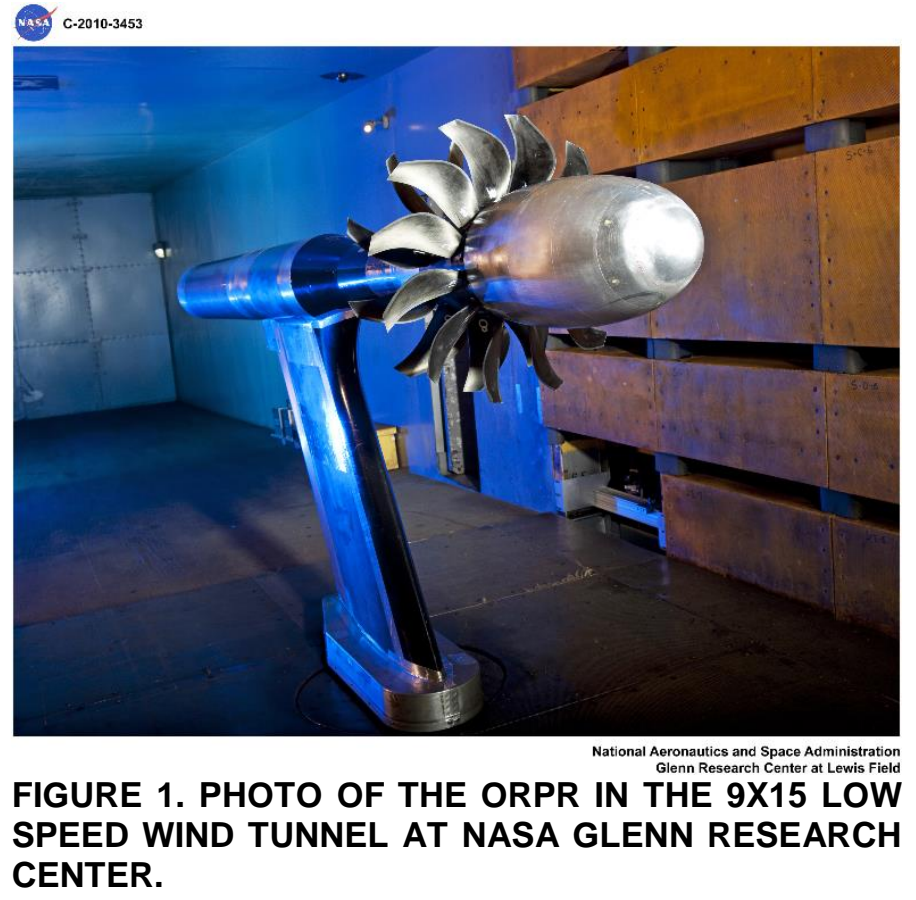

1

This material is declared a work of the U.S. Government and is not subject to copyright protection in the United States. Approved for public release; distribution is unlimited. 
The flow field of the contra rotating open rotor (CROR) has been studied by numerous researchers in recent years. Stürmer et al. looked at a generic isolated CROR with a 10 bladed front rotor and 8 bladed aft rotor [3]. They acquired a large PIV data set that was subsequently phase averaged to reconstruct a pseudo-time resolved vortex system. Stürmer et al. found an approximately $1 \%$ difference in the radial location of forward rotor tip vortex as compared to CFD simulations.

Stürmer, separately looking at a generic $8 \times 8$ bladed pusher CROR configuration, found that the complex interaction of the forward blade wakes and tip vortices with the aft rotor could be captured by the DLR TAU-code [4]. He showed that the wakes of the forward rotor are ingested by the aft rotor which leads to periodic fluctuations in the blade forces and has a strong impact on the root flow topology. It was also shown that the aft rotor thrust had larger amplitude fluctuations due to the impact of the forward rotor wakes.

Similarly, Boisard et al. produced CFD results for a CROR with a 12 front blades and 10 aft blades [5]. While the research was focused on installation effects of the CROR, they were able to accurately predict most of the time-averaged flow characteristics that were measured in experiments. The total pressure distributions on the blades matched very closely with experiments everywhere except the blade root. They also recorded that the front rotor tip vortices propagated downstream and interacted with the aft rotor to create some oscillations of the aft rotor tip vortices as shown in their Q-criteria isovalues.

Schnell et al. studied the V1.1 CROR configuration at low speed conditions and determined that their CFD was able to predict the thrust and propulsive efficiency to within 1\%-2\% [6]. They also performed an optimization in which the front rotor wakes were transformed to the aft rotor relative system and the integral wake deficit was subsequently minimized. Because the wake strength directly correlates with the unsteady blade loading, the optimized version was unloaded in the mid-span region, leading to an overall reduction in the radiated acoustics.

Uzol et al. performed PIV inside the casing of an axial turbo machine using a transparent rotor and stator built from acrylic [7]. The working fluid was a sodium iodide solution with the same optical refraction index as the blades. They took images with the rotor at 10 different locations, each $3^{\circ}$ apart. This corresponded to a single passage of the 12 bladed rotor. They then computed phase averaged flow fields and turbulence statistics. Their findings are presented in a number of subsequent papers, including [8]. They typically acquired 1000 images per rotor phase, in order to calculate converged turbulence statistics.

The importance of the aft rotor effect on the inter-rotor flow field has been considered analytically. Parry and Crighton predicted noise from a counter-rotating propeller system, specifically flyover noise from a Fairey Gannet, and found that the aft rotor potential field interacting with the front rotor was a major contributor to noise. [9] For interaction tones, those at sums of the front and aft rotor blade passing frequencies, the rear rotor potential field contribution was far larger than the front rotor viscous wake. However, the Fairey Gannet had equal and low blade count propellers that were closely spaced. The potential field interactions of that system may not be representative of contemporary open rotor systems.

This paper will discuss a method of extracting the effects of the aft rotor on the inter-rotor flow from the 2010 PIV dataset and determine those effects on the velocity field. It will also discuss the effects of the relative position of the aft rotor to forward rotor on the front rotor tip vortex and blade wakes. This is the only known experimental study which illustrates how in a modern CROR application the potential field of an aft rotor 1) varies with upstream distance, and 2) alters the blade wakes and tip vortices generated by the front rotor.

\section{EXPERIMENTAL SETUP}

The present PIV data collection effort acquired a volume of three component velocity measurements composed of 30 planes from near the hub radially outward towards the tip. The PIV cameras and laser were mounted to a traverse that allowed the entire data acquisition system to move from plane to plane. A separate PIV calibration was performed at each plane. A schematic showing the location and extent of the PIV data acquisition is given as Figure 2.

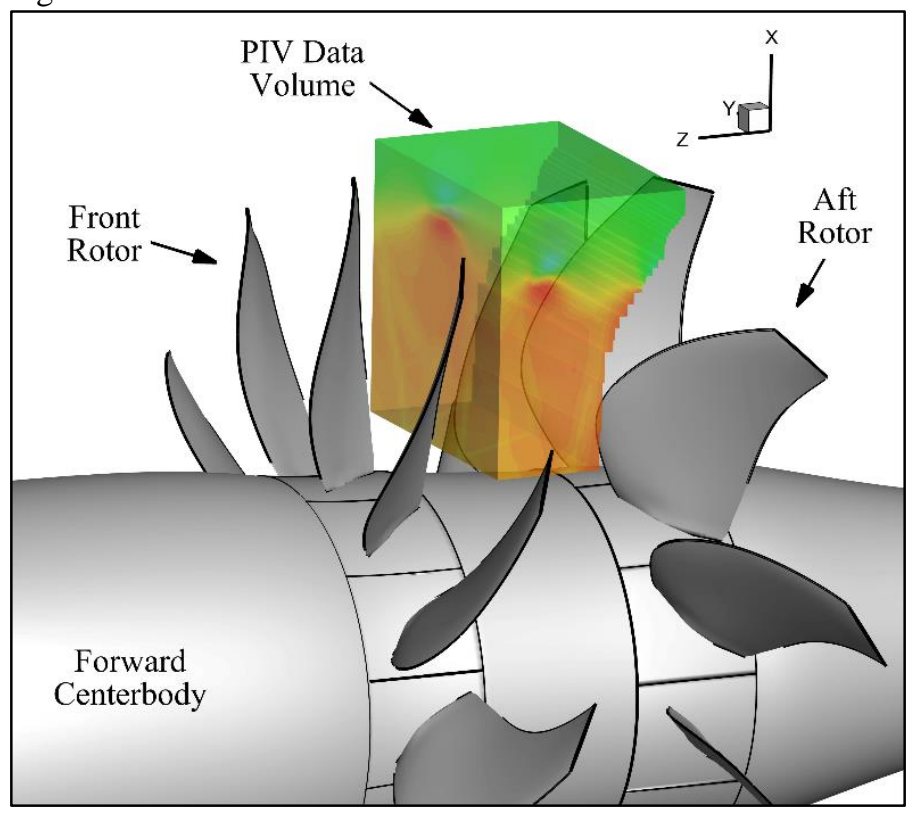

FIGURE 2. SCHEMATIC OF EXTENT OF PIV DATA ACQUISITION ON ORPR. POSITIVE Z-DIRECTION IS UPSTREAM. THE 30 PLANES OF PIV DATA ARE STACKED IN THE X-DIRECTION. FLOW IS FROM LEFT TO RIGHT.

The PIV system was triggered on the front rotor such that the front rotor was always in the same position for each acquisition event. The aft rotor position was not recorded and varied randomly during the acquisition. Both rotors were set to the same nominal rotational speed, however the use of independent air turbines to drive each shaft led to some differences in the true RPM of the two rotors. The full details of the PIV effort including calibration procedures and experimental accuracy can be found in [10]. A separate data collection effort

This material is declared a work of the U.S. Government and is not subject to copyright protection in the United States. Approved for public release; distribution is unlimited. 
included extensive acoustic measurements, as detailed in [11]. The details of the PIV test matrix are shown in Table 1. The tunnel freestream Mach number was 0.20 for all PIV data. The performance of the rotor under the various test conditions is given in Table 2.

This same PIV dataset was previously analyzed and compared with CFD simulations of the ORPR by Van Zante and Envia [12]. It was found that near the front rotor, the PIV data and CFD simulations compared favorably. However, near the aft rotor, significant differences were found. Specifically, the time averaged PIV front rotor wake velocity deficit did not capture the dynamics that were found in the time dependent CFD simulations. It was shown that the dynamics of the front rotor blade wakes can have a significant impact on the radiated acoustics, therefore it is imperative to know and understand the full effects of the aft rotor on the inter-rotor flow field. Additionally, some CAA methodologies, such as discussed in Ref. [2], rely on isolated blade row calculations to provide the flow field perturbations. In that methodology, the forward rotor wake/tip vortex must be extracted from the CFD simulation at an axial location that is outside any significant influence of the aft rotor potential field.

TABLE 1. TEST MATRIX FOR PIV DATA ACQUISITION.

\begin{tabular}{|c|c|c|c|c|}
\hline $\begin{array}{c}\text { Test } \\
\text { Case }\end{array}$ & $\begin{array}{c}\text { Model } \\
\text { Configuration }\end{array}$ & $\begin{array}{c}\text { Blade Angle } \\
\text { of Attack, } \\
\text { Front/Aft }\end{array}$ & $\begin{array}{c}\text { Rotor } \\
\text { RPM }\end{array}$ & $\begin{array}{c}\text { Front Rotor } \\
\text { PIV Delay } \\
\text { Phase Step }\end{array}$ \\
\hline 1 & Take Off & $40.1^{\circ} / 40.8^{\circ}$ & 6444 & $0^{\circ}$ \\
\hline 2 & Take Off & $40.1^{\circ} / 40.8^{\circ}$ & 6453 & $14.7^{\circ}$ \\
\hline 3 & Take Off & $40.1^{\circ} / 40.8^{\circ}$ & 5680 & $0^{\circ}$ \\
\hline 4 & Take Off & $40.1^{\circ} / 40.8^{\circ}$ & 5684 & $16.7^{\circ}$ \\
\hline 5 & Approach & $33.5^{\circ} / 35.7^{\circ}$ & 5704 & $0^{\circ}$ \\
\hline 6 & Approach & $33.5^{\circ} / 35.7^{\circ}$ & 5707 & $18.1^{\circ}$ \\
\hline
\end{tabular}

TABLE 2. PERFORMANCE OF THE OPEN ROTOR SYSTEM UNDER THE VARIOUS TEST CASES WHERE PIV DATA WAS ACQUIRED

\begin{tabular}{|c|l|l|l|l|l|}
\hline $\begin{array}{l}\text { Test } \\
\text { Cases }\end{array}$ & $\begin{array}{l}\text { Front } \\
\text { Rotor } \\
\text { Thrust } \\
(\mathrm{kN})\end{array}$ & $\begin{array}{l}\text { Front } \\
\text { Rotor } \\
\text { Torque } \\
(\mathrm{N} \cdot \mathrm{m})\end{array}$ & $\begin{array}{l}\text { Aft } \\
\text { Rotor } \\
\text { Thrust } \\
(\mathrm{kN})\end{array}$ & $\begin{array}{l}\text { Aft } \\
\text { Rotor } \\
\text { Torque } \\
(\mathrm{N} \cdot \mathrm{m})\end{array}$ & $\begin{array}{l}\text { Total } \\
\text { Shaft } \\
\text { Power } \\
(\mathrm{kW})\end{array}$ \\
\hline 1 & 1.296 & 229.9 & 1.288 & 221.4 & 310.7 \\
\hline 2 & 1.296 & 230.3 & 1.290 & 222.7 & 311.9 \\
\hline 3 & 0.867 & 154.0 & 0.848 & 150.1 & 184.4 \\
\hline 4 & 0.868 & 154.3 & 0.848 & 150.8 & 184.9 \\
\hline 5 & 0.468 & 71.3 & 0.452 & 71.2 & 87.0 \\
\hline 6 & 0.466 & 71.2 & 0.452 & 70.6 & 86.7 \\
\hline
\end{tabular}

\section{DETERMINATION OF AFT ROTOR POSITION}

Knowledge of the relative position of the aft rotor to the fixed front rotor was necessary to determine the effects of the aft rotor. No specific signal or other data was recorded to track the position of the aft rotor during the PIV data acquisition. The raw PIV images contain the only record of the position of the aft rotor. An image processing algorithm was developed to extract the position information from the raw PIV images. The PIV laser sheet was masked to illuminate only a portion of the inter-rotor flow field so as not to damage the composite material of the blades. This meant that a portion of the raw images was not illuminated directly by the laser but rather indirectly by reflections off of the PIV seeding particles and other surfaces. The indirect illumination was sufficient to see details of the aft rotor blades in the camera's field of view and plane of focus. Only the raw images from the second PIV exposure of the backscattered camera were processed. This exposure captured the maximum amount of reflected light. A representative raw PIV image is shown in Figure 3.

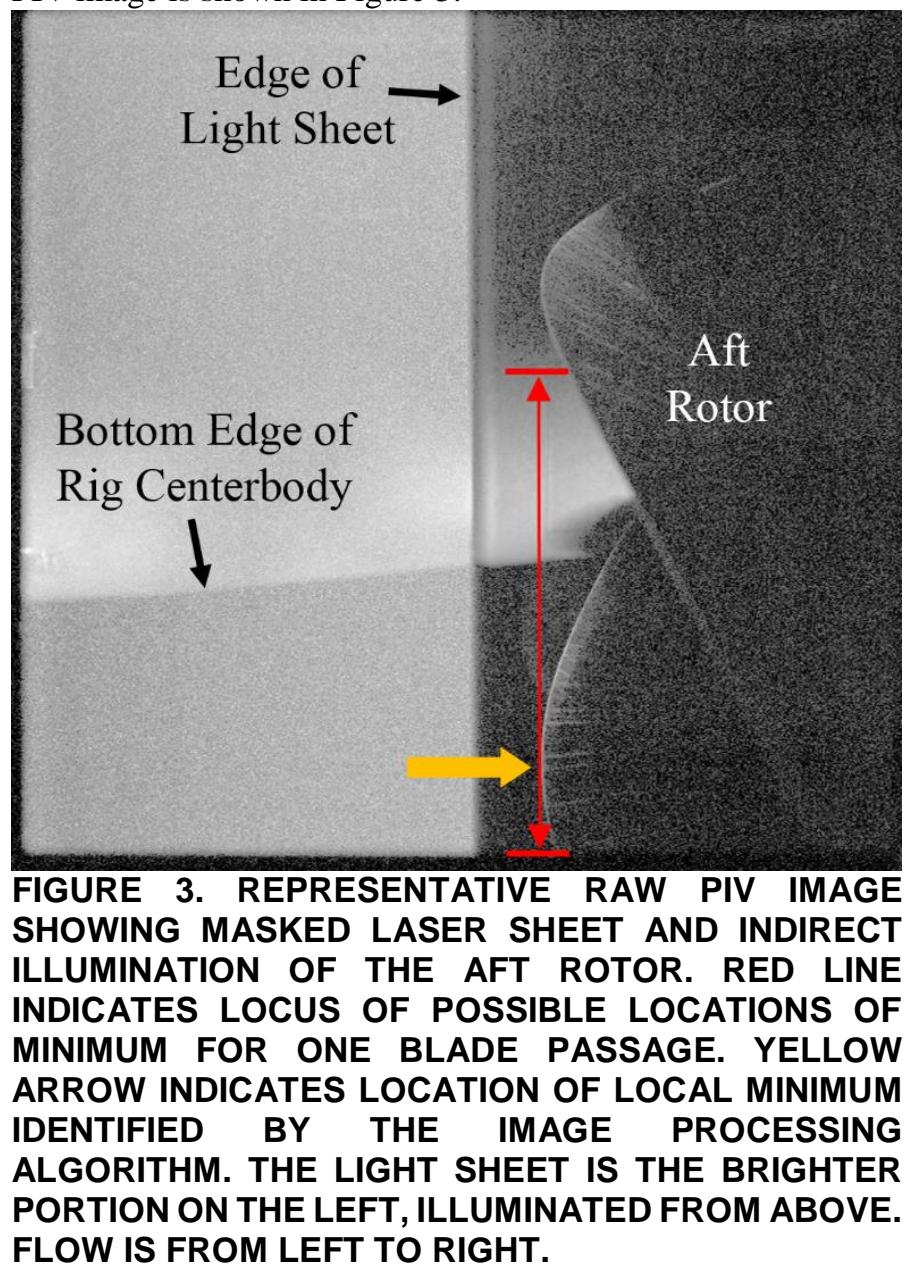

The flow is moving from the left to the right of the image while two blades of the aft rotor are visible in the right hand portion of the image. The aft rotor is spinning from bottom to top. The left half of the image shows the PIV seeding particles illuminated by the laser sheet, which is masked from hitting the aft rotor.

Based upon these images, and with the knowledge of the relative positions of the ORPR and PIV cameras, an algorithm was developed to track specific features of the blade geometry and determine the relative phase angle of the aft rotor. The

3

This material is declared a work of the U.S. Government and is not subject to copyright protection in the United States. Approved for public release; distribution is unlimited. 
specific feature that was tracked depended upon the plane of PIV data acquisition. As the cameras and laser sheet moved radially outward, the perspective of the camera shifted and the laser sheet was unmasked to increase the field of view, following the aft blade sweep. The unmasking of the laser sheet resulted in less of the image being available for processing in the planes near the tip. Subsequently, only 25 of the 30 planes acquired could be processed based upon the unmasked portion of the image.

In the image shown in Figure 3, which was acquired at the plane closest to the hub of the ORPR, the feature that could be tracked was the local minimum in the camera's field of view of the blade furthest to the right hand side of the image. The horizontal position of the local minimum yielded the relative phase of the aft rotor. Due to the geometry of the rotor and the viewing angle of the camera, the location of the minimum could only be located over a known locus of points, represented by the red line in Figure 3, with the position of the minimum related directly to aft rotor phase angle. The location of the minimum in the example figure is shown with a yellow arrow. As the planes moved radially outward, the feature tracked was changed to the intersection of the straight portion of the blade with the top edge of the field of view. Each plane required its own specific geometric transformation to determine the absolute phase between the two rotors.

The PIV data acquisition included 400 image pairs in each of the 25 planes processed. Each image was assigned a phase angle based upon the image processing scheme outlined above. The phase angle was assigned between $0^{\circ}$ and $36^{\circ}$. The aft rotor contained ten blades and the focus of this study was on a single blade passage that would cover one tenth of the total annulus, or $36^{\circ}$. No attempt was made to distinguish the 10 aft blades from each other. After all 400 images in the plane had been assigned a phase angle, the corresponding vector maps were placed into one of ten bins of width $3.6^{\circ}$, yielding approximately 40 vector maps per bin. A representative histogram of the number of vector maps per bin is shown in Figure 4.

Each bin was subsequently ensemble averaged to generate a single phase averaged vector map for that particular bin and PIV plane. After the phase averaged vector maps for each bin and plane were calculated, the full three dimensional dataset was reconstructed at each phase bin for a total of ten discrete volumes of data.

In order to have something to compare to, it is instructive to consider the non-phase averaged data before analyzing the phase averaged dataset. The overall average data volume, with the aft rotor phase effect averaged in is given in Figure 5. This image shows contours of velocity magnitude in a plane as well as two isosurfaces of velocity, where velocity magnitude is the resultant of all three velocity components. Velocity has been normalized by the front rotor tip velocity, $V_{l, t i p}$. Length has been normalized by the front rotor radius, $R_{l}$. The front rotor location is $z / R_{l}=0$ and the aft rotor is at $z / R_{l}=0.61$. The plane shown in Figure 5 is located at $z / R_{l}=-0.4$. The two isosurfaces show speeds of $U_{M} / V_{l, t i p}=0.35$ and 0.56 . The choice of these isosurfaces was made to best observe the potential field of the aft rotor in two distinct regions of interest.

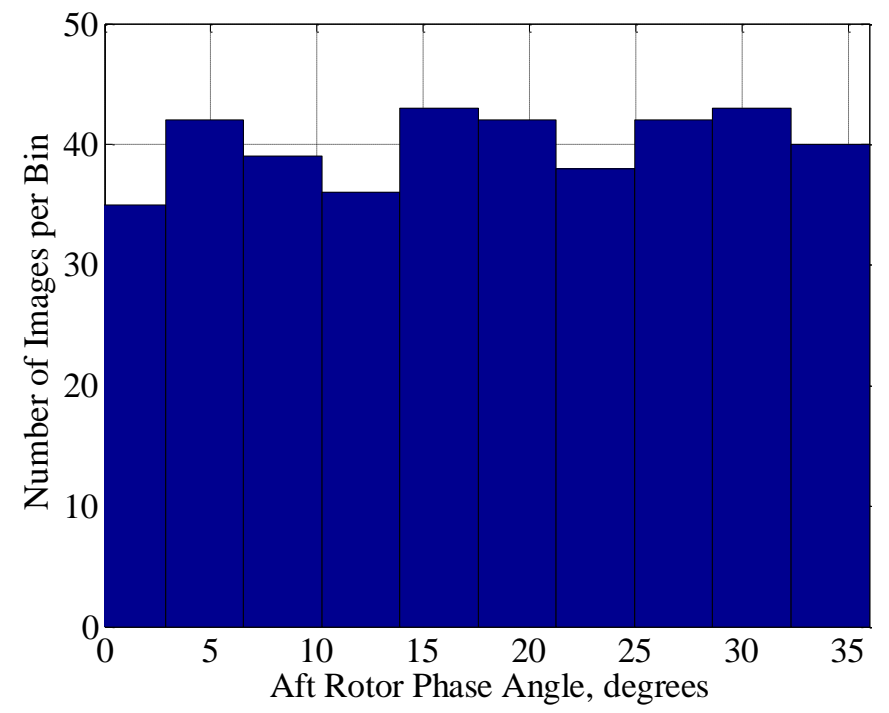

FIGURE 4. REPRESENTATIVE HISTOGRAM SHOWING NUMBER OF VECTOR MAPS PER BIN USED TO ENSEMBLE AVERAGE THE DATA BASED ON AFT ROTOR PHASE ANGLE. EXAMPLE SHOWN IS FROM TEST CASE 1, PLANE 9 FROM THE HUB.

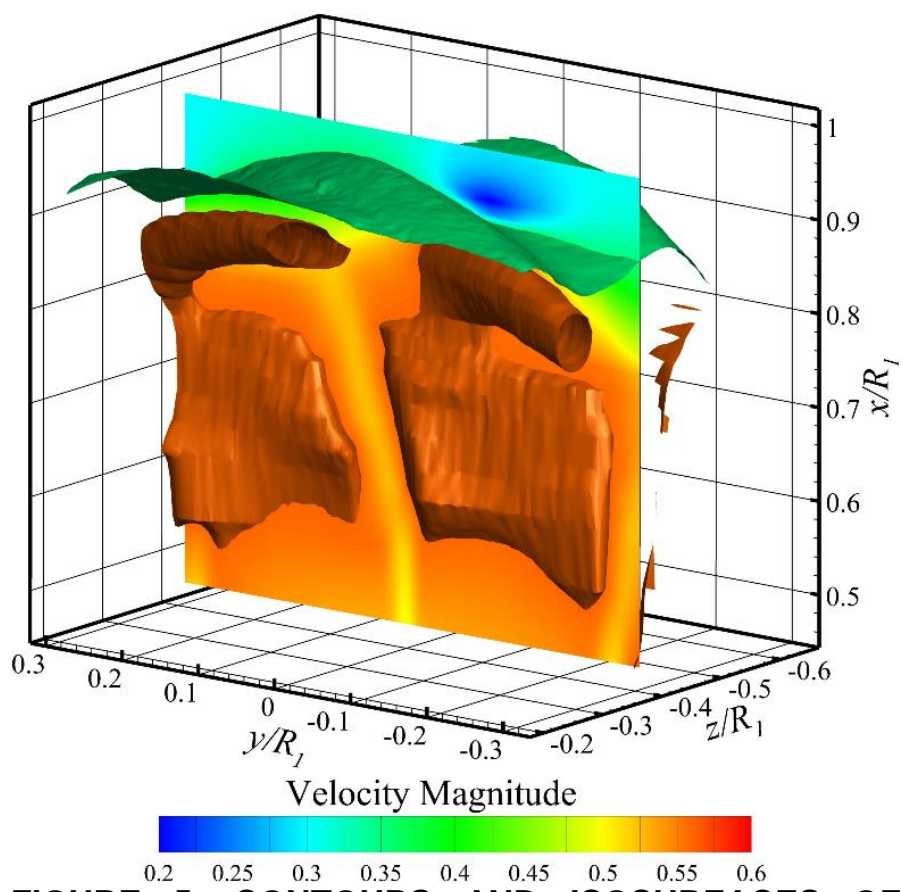

FIGURE 5. CONTOURS AND ISOSURFACES OF VELOCITY MAGNITUDE FOR NON-PHASE AVERAGED DATASET, TEST CASE 1. ISOSURFACES ARE AT $U_{M} / V_{1, \text { TIP }}=0.35$ AND 0.56. PLANE IS LOCATED AT $Z / R_{1}=-0.4$ BEHIND FORWARD ROTOR.

The two tubular isosurfaces near the top of the flow field in Figure 5 are the tip vortices from the forward rotor. The presence of the tip vortices creates the wavy nature of the isosurface at $U_{M} / V_{l, t i p}=0.35$ that follows the path of the vortices. Two wakes

\section{4}

This material is declared a work of the U.S. Government and is not subject to copyright protection in the United States. Approved for public release; distribution is unlimited. 
from the front rotor blades are also visible in the plane as velocity deficits that extend radially outward. The PIV field of view was such that it captured two of the wakes from the 12 bladed front rotor.

The final structure of interest in Figure 5 is the isosurface at $U_{M} / V_{l, t i p}=0.56$ that occurs between $5.5<x / R_{l}<7.5$ in the radial direction. This isosurface appears to be split by the wakes, which is to be expected given the nature of the velocity deficit in the wake. The extent of this isosurface is relatively constant in the radial direction. There is no ready explanation for the general topography of this particular isosurface when only the time averaged PIV data set is available. However, this is the region of interest for the effects of the potential field of the aft rotor. This particular isosurface can be explained by the dynamics of the relative motions of the forward and aft rotors, as discussed next.

\section{AFT ROTOR PHASE AVERAGED PIV DATA ANALYSIS}

It was possible to determine the effects of the aft rotor on the inter-rotor flow field after successful phase averaging of the data. The magnitude of velocity was chosen as the first variable of interest because it allows the potential field of the aft rotor to be observed in a relatively simple fashion. The specific results included and discussed are from Test Case 1, which has the highest blade loading and shows the most dramatic effect of aft rotor phase angle compared to the lower RPM cases.

Figure 6 shows the aft rotor phase averaged data at five different relative phase angles at the same axial plane and with

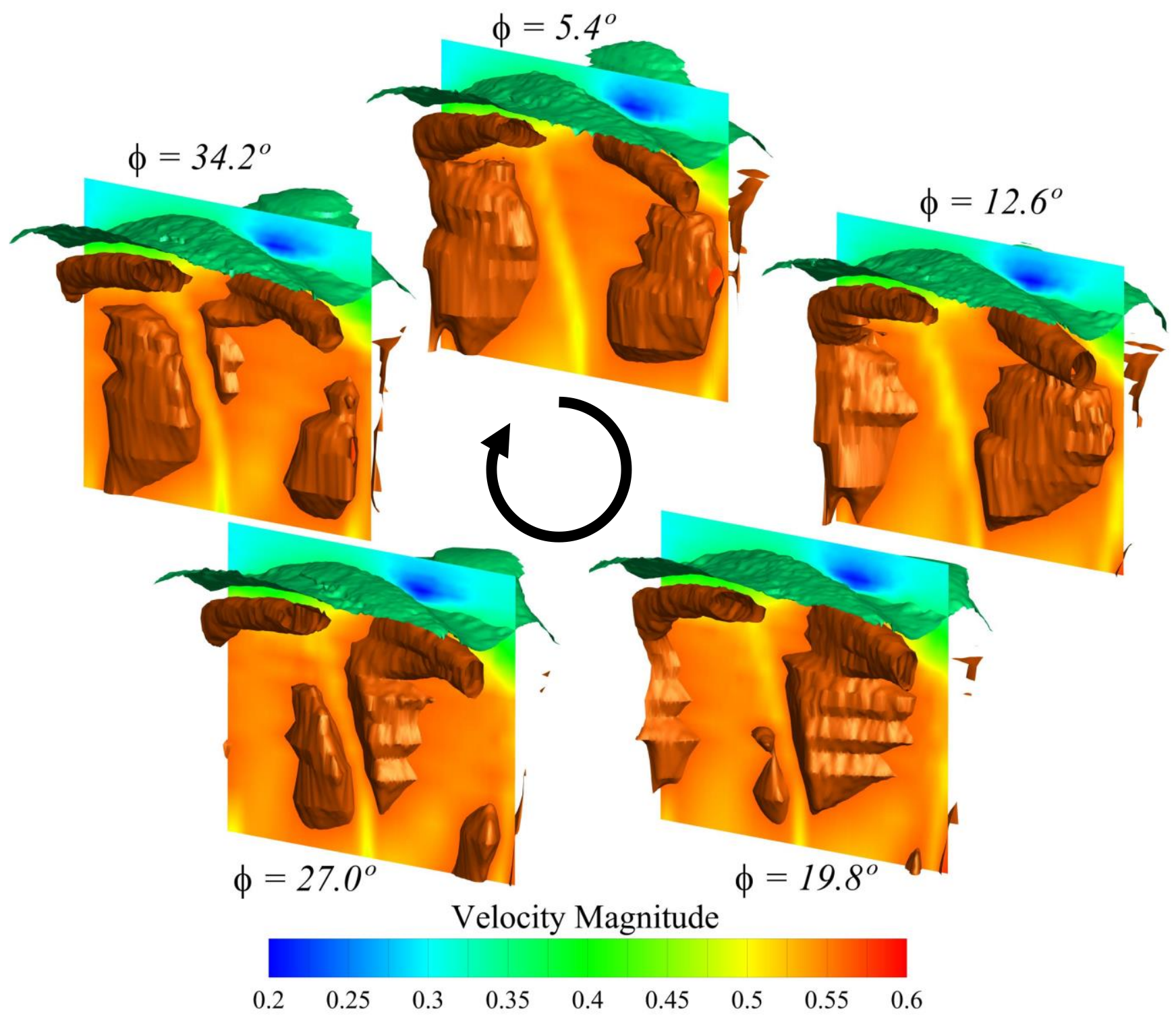

FIGURE 6. CONTOURS AND ISOSURFACES OF VELOCITY MAGNITUDE FOR THE AFT ROTOR PHASE AVERAGED TEST CASE 1 AT 5 DIFFERENT AFT ROTOR PHASE ANGLES. ISOSURFACES ARE AT $\mathrm{U}_{\mathrm{M}} / \mathrm{V}_{1, \text { TIP }}$ $=0.35$ AND 0.56 .

5

This material is declared a work of the U.S. Government and is not subject to copyright protection in the United States. Approved for public release; distribution is unlimited. 
the same isosurfaces of velocity magnitude as shown in Figure 6. It should be noted here that the aft rotor is spinning in the counterclockwise direction when looking downstream. The dynamics of the aft rotor potential field can now be readily observed.

The potential field of the aft rotor manifests as the $U_{M} / V_{l, t i p}=0.56$ isosurface that travels with the rotation of the aft rotor. In Figure 5, this particular isosurface was smeared in the azimuthal direction. However, Figure 6 shows the dynamics of the flow field as the relative phase angle changes. The isosurface travels ahead of the aft rotor blade and is a coherent structure that convects across the field of view. When it passes through the wakes of the forward rotor, the isosurface appears to be cut in two. The potential field also has the effect of raising the local velocity when the isosurface is passing through the wake. Between the coherent structures formed by two sequential aft rotor blades is a local velocity deficit that follows behind the blades. When this deficit passes through the wake, it has the effect of lowering the local velocity. This causes cyclic variations of the wake velocity profile that is ingested by the aft rotor. A quantitative analysis of this effect will be discussed in greater detail in a subsequent section.

Another manifestation of the aft rotor potential field can be seen in the $U_{M} / V_{l, t i p}=0.35$ isosurface in the upper right hand corner of each image. As the aft rotor blade passes this location, a large coherent structure rises up and convects azimuthally with the aft rotor blade. This structure is not present in Figure 5 and shows another dynamic aspect of the flow field only observable in the phase averaged data.

The effects of the aft rotor on the forward rotor tip vortices can also be observed in Figure 6. A close study of the images of Figure 6 shows the tip vortices exhibiting a "breathing" mode in which they seem to expand and contract in this particular isosurface of velocity. The affect appears to be small, but measureable. Any change in the behavior of the tip vortices can have a large impact on the radiated acoustics. A quantitative analysis of the effects on the tip vortices will be presented in a subsequent section.

\section{STREAMWISE EFFECT OF AFT ROTOR PHASE FOR TEST CASES 1 AND 5}

A streamwise and cross-stream slice of the inter-rotor flow field is given in Figure 7, to quantify the streamwise extent of the aft rotor blade influence. The data presented is from plane number 9 , which is at $x / R_{1}=0.78$ from centerline of the model, near mid-span of the blades. The aft rotor leading edge is approximately at $z / R_{l}=-0.57$ at this radius, while the front rotor trailing edge is at about $z / R_{l}=-0.08$. The velocity magnitude shown in Figure 7 reveals a velocity magnitude increase of about $9 \%$ (from $0.53 V_{1, \text { tip }}$ to $0.58 V_{l, t i p}$ ) as the aft rotor potential field passes across the measurement domain. Of the ten phase averages calculated, numbers four and nine are shown, corresponding to opposite aft rotor blade phase angles. The wake from the front rotor is stationary while the aft rotor potential field passes through it.
Figure 8 shows a line graph extracted from Figure 7 to illustrate the streamwise extent of the influence of the aft rotor on the axial velocity, $U_{W}$. All ten phases are shown in gray, plus the time mean data, which is shown in red. The ends of the curves intersect the front rotor wake on both upstream (near $z / R_{l}$ $=-0.2$ ) and downstream ends (near $z / R_{l}=-0.47$ ). The effect of the aft rotor phase is about $\pm 0.025 V_{l, t i p}$ out of $0.54 V_{l, t i p}$ at $z / R_{l}$ $=-0.5$, corresponding to about $5 \%$ variation. The effect diminishes quickly away from the aft rotor, and is only about \pm $0.03 V_{l, t i p}$ at $z / R_{l}=-0.25$. This distance is about $2 / 3$ of the aft to forward separation between the rotor blade surfaces at this span location, indicating that the rotors are spaced far enough apart that the potential field interaction is small.
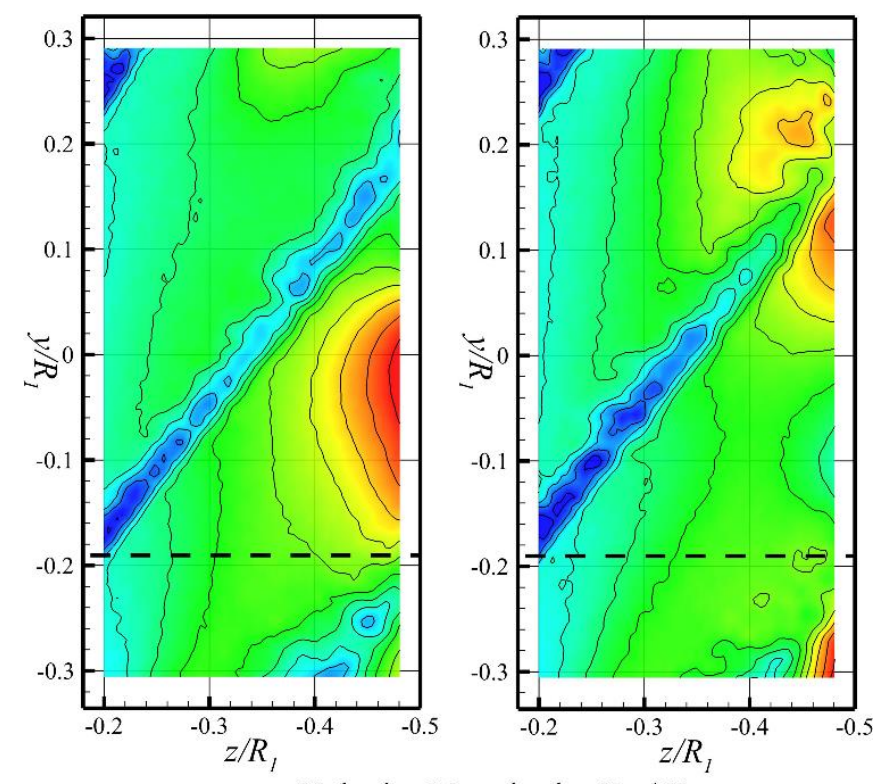

Velocity Magnitude, $V_{M} / V_{l, t i p}$

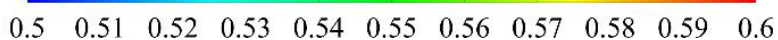

FIGURE 7. EFFECT OF AFT ROTOR PHASE ON INTERROTOR VELOCITY MAGNITUDE, FROM TEST CASE 1. FLOW IS FROM LEFT TO RIGHT OF IMAGE. THE FORWARD ROTOR IS MOVING TOP TO BOTTOM, THE AFT ROTOR IS MOVING BOTTOM TO TOP. LEFT IMAGE IS OF OPPOSITE PHASE FROM RIGHT IMAGE. DASHED LINE AT $Y / R_{1}=-0.183$ SHOWS DATA EXTRACTION LINE FOR FIGURE 8-FIGURE 10.

The radial and tangential velocities are shown in Figure 9 and Figure 10, respectively. The radial velocity is negative, indicating flow towards the rotor hub. The effect of the aft rotor phase on these velocity components is proportionally bigger, more than $\pm 15 \%$ radially and $\pm 20 \%$ tangentially. The aft rotor disturbance does not affect the forward rotor, decaying to \pm 0.03 $V_{1, t i p}$ by $z / R_{1}=-0.25$, similar to the axial velocity. A closer spacing could be a concern for aeroacoustics, as the aft field potential field impacting the forward blade would be a strong noise source.

6

This material is declared a work of the U.S. Government and is not subject to copyright protection in the United States. Approved for public release; distribution is unlimited. 


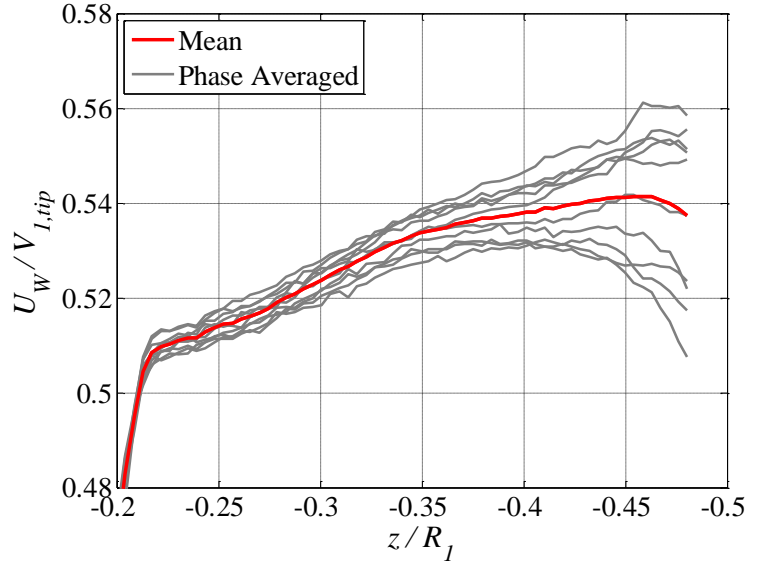

FIGURE 8. STREAMWISE VELOCITY VARIATION WITH AFT ROTOR POSITION. VALUES EXTRACTED FROM A LINE AT $Y / R_{1}=-0.183$ FROM FIGURE 7, AT ALL 10 AFT ROTOR PHASES.

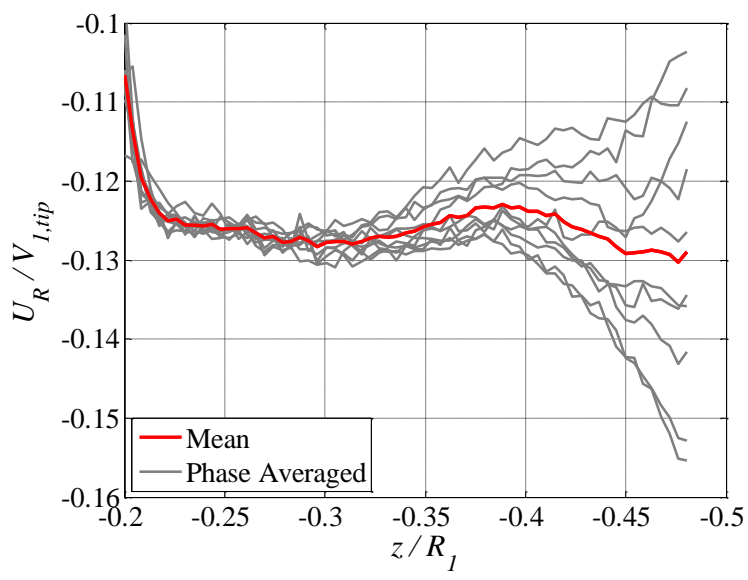

FIGURE 9. RADIAL VELOCITY VARIATION WITH AFT ROTOR POSITION. VALUES EXTRACTED FROM A LINE AT Y/R $1=-0.183$ FROM FIGURE 7, AT ALL 10 AFT ROTOR PHASES.

Johnston and Fleeter [13] measured unsteady pressure fluctuations in the proximity of a rotor and noted that the potential field disturbances should decay exponentially in both upstream and downstream directions. In the present experiment, the fluctuations of axial velocity were quantified by calculating the standard deviation across the 10 rotor phases, for each of the streamwise measurement locations. This result is shown in Figure 11, and compared with the expected exponential decay functional form. It can be seen that an exponential fit cannot quite capture the shape of the data, and this is consistent with the findings of Johnson and Fleeter who found the potential gust did not decay to zero in the upstream direction as predicted (see Figure 11 of [13]). They attributed this effect to an acoustic interaction between the rotor and upstream guide vane row. In the present case, the asymptote of the data is probably due to the inflow turbulence level.

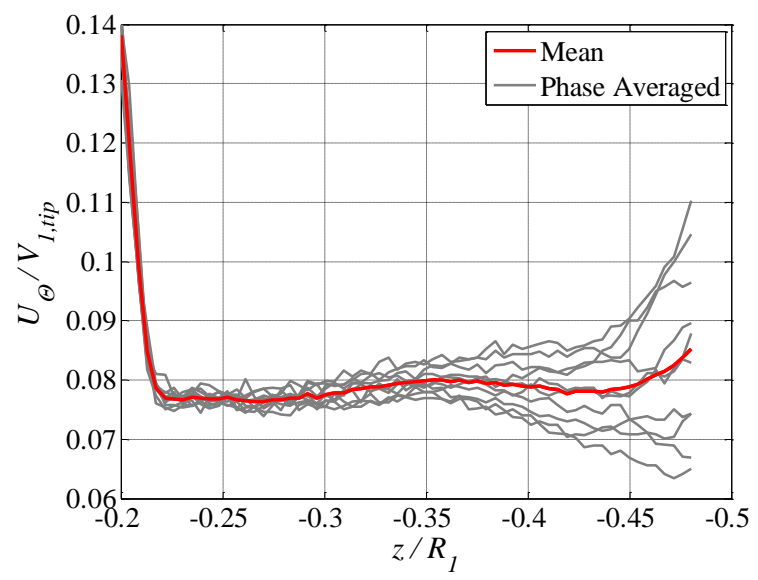

FIGURE 10. TANGENTIAL VELOCITY VARIATION WITH AFT ROTOR POSITION. VALUES EXTRACTED FROM A LINE AT $Y / R_{1}=-0.183$ FROM FIGURE 7, AT ALL 10 AFT ROTOR PHASES.

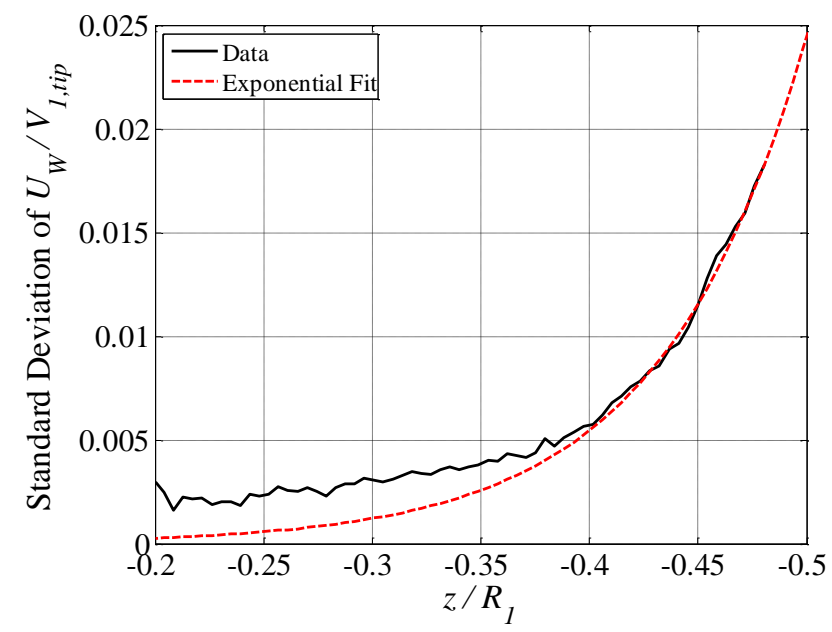

FIGURE 11. DECAY OF AFT ROTOR POTENTIAL FIELD AS QUANTIFIED BY FLUCTUATIONS IN $U_{W}$. AFT ROTOR LEADING EDGE IS AT Z/R1 = -0.57.

The noise spectrum from the NASA ORPR with F31/A31 blades has been analyzed by Elliott [14], and is known to have substantial number of interaction tones. These are caused by aerodynamic interactions, categorized by Hanson as viscous wakes, shed potential wakes, and bound potential effects [15]. It is readily expected that the aft rotor will generate noise due to all three of these effects. The front rotor on the other hand will only create interaction noise due to the aft rotor potential field. The "culprit" for the noise contribution at various tones has been investigated by two different methods. Horváth [16] and Horváth et al. [17] used a phased microphone array positioned broadside to the fan blades to identify the noise source location for each tone, as shown in Figure 16 of [16]. Most interaction tones were

7

This material is declared a work of the U.S. Government and is not subject to copyright protection in the United States. Approved for public release; distribution is unlimited. 
found to be radiating from the aft rotor, but several strong tones came from the front rotor. These were always tones with a higher multiple of the front rotor blades. For example, the tone at shaft order 34 is twice the front blade count plus the aft rotor blade count $(2 \times 12+10)$ and radiates from the front blade.

Another method for identifying the rotor responsible for a particular tone was investigate by Stephens and Vold [18], who used an order tracking filter to quantify the portion of the noise signal that was coherent with each rotor shaft. This was possible because the ORPR is air driven and the two shafts jitter during operation. As seen in Figure 16 of [18], several interaction tones were found to be coherent with the front rotor, including shaft orders 34 and 36. These tones are expected to be strongly affected by the rotor spacing.

The ORPR includes features for changing the rotor spacing, but it was not used with F31/A31 during the recent test campaign. In the 1980's, this effect was documented with an earlier set of blades. The same 2-forward blade count plus 1-aft blade count shaft order tone was found to be most sensitive to rotor spacing, see Figure 16 of [19].

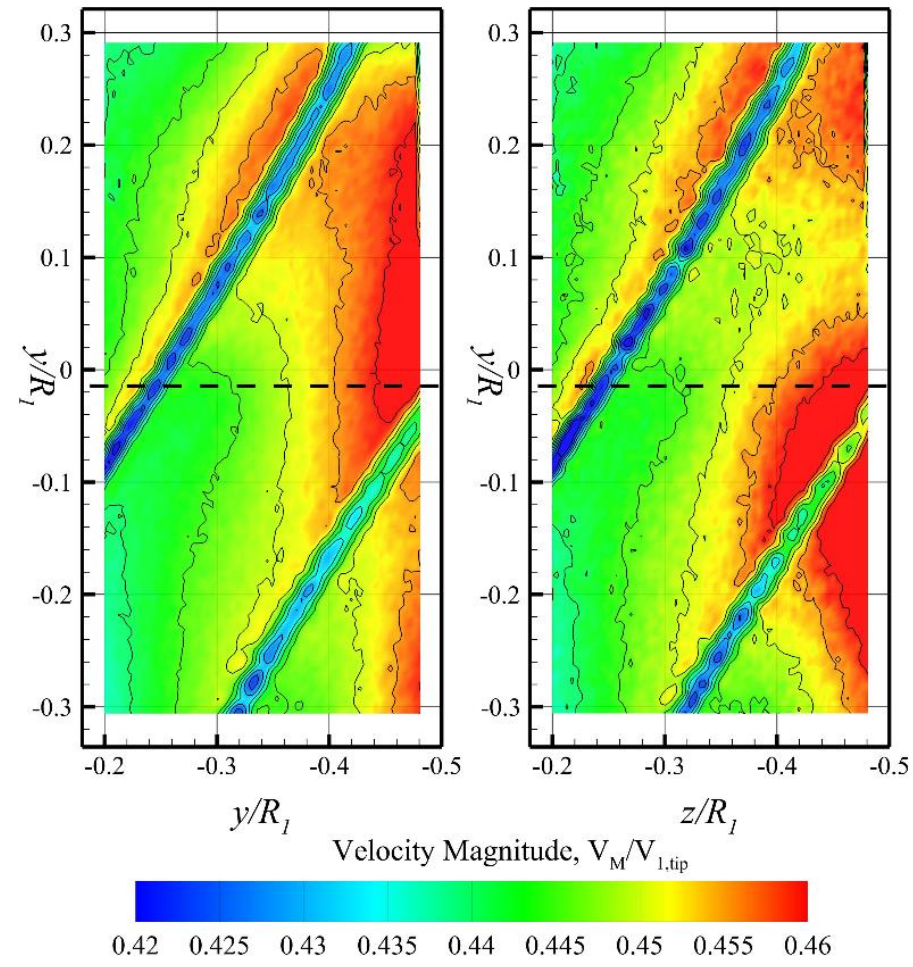

FIGURE 12. INTER-ROTOR VELOCITY MAGNITUDE, FROM TEST CASE 5. FLOW IS FROM LEFT TO RIGHT OF IMAGE. THE FORWARD ROTOR IS MOVING TOP TO BOTTOM, THE AFT ROTOR IS MOVING BOTTOM TO TOP. DASHED LINE AT $Y / R_{1}=-0.01$ SHOWS DATA FOR LINE PLOTS GIVEN IN FIGURE 13 THROUGH FIGURE 15.

A similar set of results is presented for the rotor at approach pitch angles (Test Case 5), in Figure 12 through Figure 15. Compared to the take-off condition, the approach condition is around $1 / 3$ the thrust and torque, see Table 2. As seen in Figure 12, the smaller blade pitch settings leads to the blade wakes passing through the PIV data volume at a shallower angle. Also, the blade wakes are much narrower and smaller in magnitude, corresponding to lower thrust levels.

At approach operation conditions, the variation in $U_{W}$ is only about $\pm 0.01 V_{l, t i p}$ at $z / R_{l}=-0.5$ (the downstream edge of the PIV measurement domain), which is about $2 \%$ of the mean axial velocity at this location as shown in Figure 13. This compares with $5 \%$ as previously quantifies for take-off conditions. The radial and tangential variations at $z / R_{l}=-0.5$, as seen in Figure 14 and Figure 15, are about $10 \%$ and $20 \%$ respectively. The reduced radial variation is reasonable, since the rotor thrust at this operating condition is only a third of that generated under the take-off condition. The tip speed at approach is still $88 \%$ of the take-off tip speed, with the difference in thrust accounted for by the blade pitch angle.

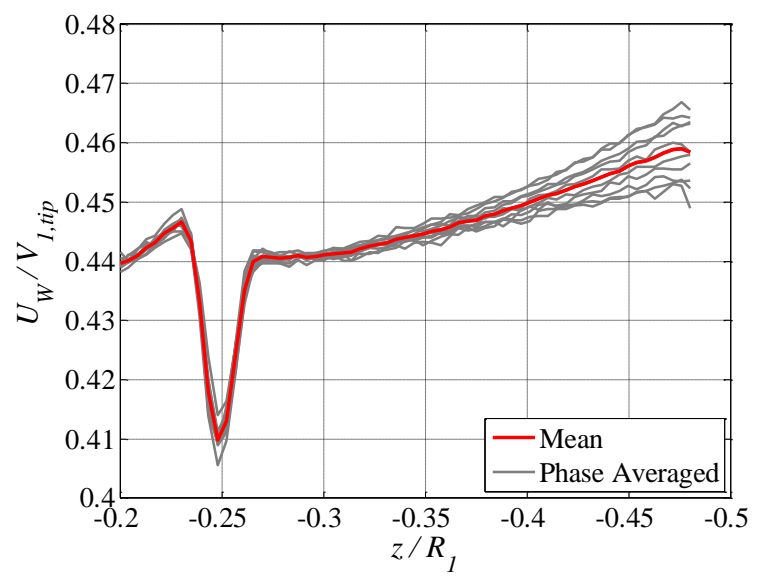

FIGURE 13. STREAMWISE VELOCITY VARIATION WITH AFT ROTOR POSITION. VALUES EXTRACTED FROM A LINE AT $Y / R_{1}=-0.01$ FROM FIGURE 12, AT ALL 10 AFT ROTOR PHASES.

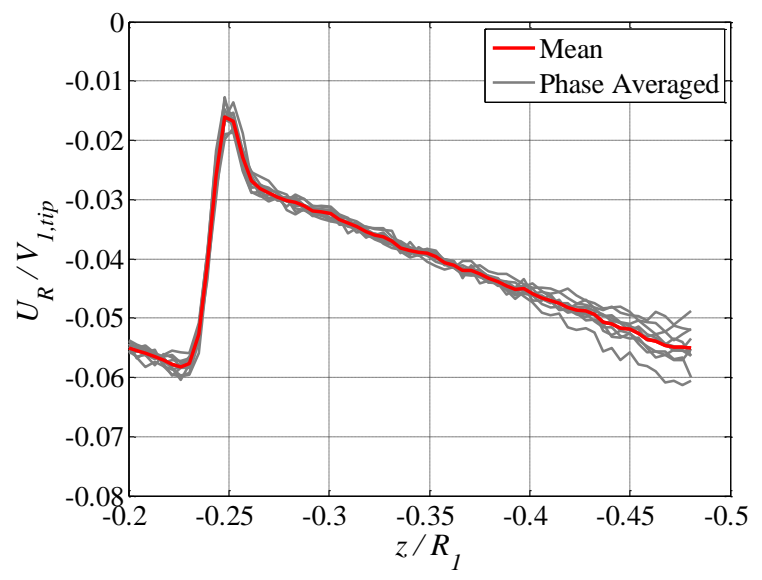

FIGURE 14. RADIAL VELOCITY VARIATION WITH AFT ROTOR POSITION. VALUES EXTRACTED FROM A LINE AT Y/R $1=-0.01$ FROM FIGURE 12, AT ALL 10 AFT ROTOR PHASES.

8

This material is declared a work of the U.S. Government and is not subject to copyright protection in the United States. Approved for public release; distribution is unlimited. 


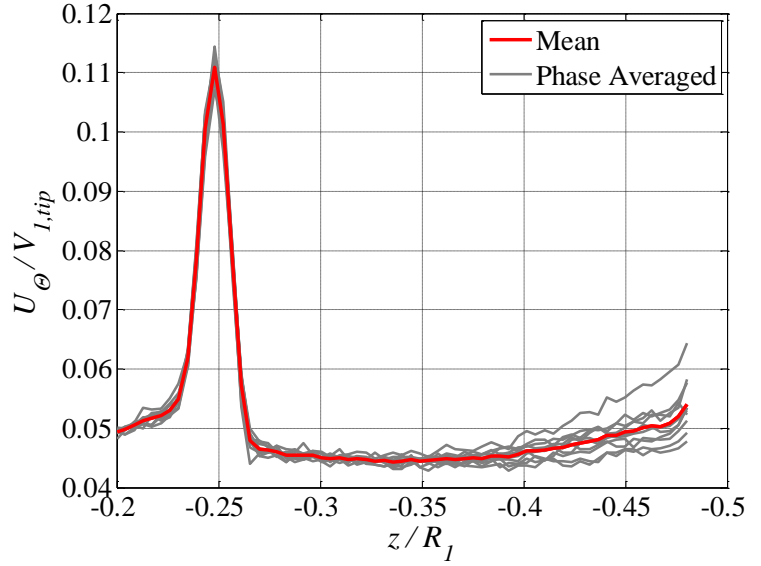

FIGURE 15. TANGENTIAL VELOCITY VARIATION WITH AFT ROTOR POSITION. VALUES EXTRACTED FROM A LINE AT $Y / R_{1}=-0.01$ FROM FIGURE 12, AT ALL 10 AFT ROTOR PHASES.

The decay of the aft rotor potential field at approach conditions was found to have a nearly identical functional form as that from take-off conditions, presented in Figure 11. The magnitude of the standard deviation at approach was one-third the level of the take-off value, corresponding extremely closely to the thrust ratio between the two conditions.

\section{COMPARISON OF MEASURED FORWARD ROTOR WAKE PROFILE WITH CFD SIMULATION}

The axial velocity was extracted along a line of constant radius in both the PIV data and CFD simulations in order to quantitatively examine the forward rotor wakes. A difference in the behavior of the forward rotor wakes was found when the nonphase averaged data was compared with instantaneous CFD wake profiles along the line of constant radius [12]. Figure 16 shows contours of axial velocity for a single phase of the aft rotor phase averaged data with a white dashed line showing the constant radius along which the wake profile was extracted. The data were extracted from an axial plane located 2.25 inches upstream of the aft rotor pitch change axis $\left(z / R_{l}=-0.4\right)$. The PIV data on this plane had a limited radial extent due to the proximity to the aft rotor.

Figure 17 shows a comparison of the aft rotor phase averaged data and the CFD simulations from [12]. Both Figure 17 (A) and (B) show the time averaged PIV wake profile as a single black curve. The CFD instantaneous profiles shown in Figure 17 (A) (dashed lines) did contain information about the effects of the potential field on the wake. Certain features showing a complex velocity field that did not appear to be a traditional, steady state blade wake, were found in the CFD that were not present in the non-phase averaged PIV data. These features were assumed to be caused by the interaction of the aft rotor potential field with the wake, but the lack of data at various relative phase angles between the forward and aft rotors prevented any further comparison between the two datasets [12].

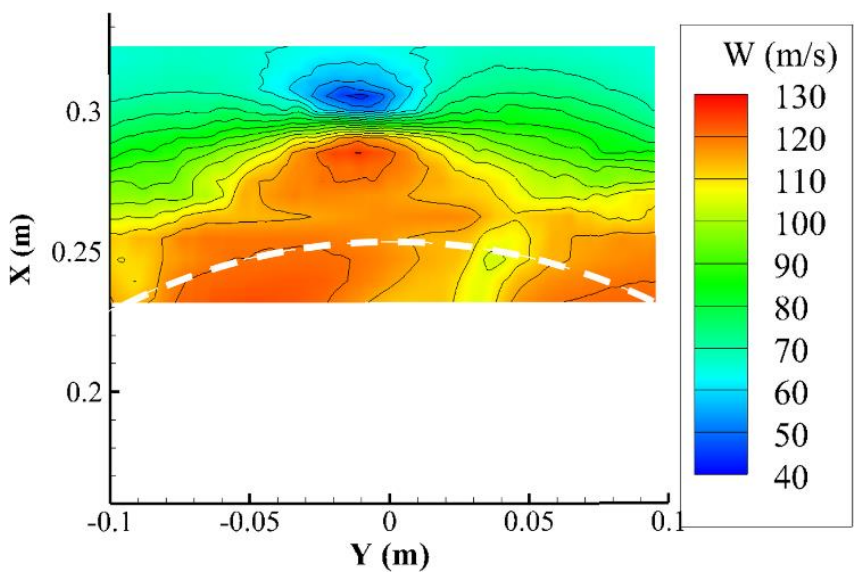

FIGURE 16. CONTOURS OF AXIAL VELOCITY AT A PLANE 2.25 INCHES UPSTREAM OF THE AFT ROTOR PITCH CHANGE AXIS. FIGURE TAKEN FROM REF. [12]. DASHED LINE OF CONSTANT RADIUS SHOWS LOCATION OF DATA PLOTTED IN FIGURE 17.

The aft rotor phase averaged data were extracted along the same constant radius line for all ten phase bins and were plotted with the mean PIV wake profile shown in Figure 17 (B). Only three of the relative phases were plotted for clarity and were chosen to most closely agree with the instantaneous CFD profiles of Figure 17 (A). The aft rotor phase angles for the three instantaneous CFD wake profiles was not given in Figure 17, so the demonstrated agreement is largely qualitative. The instantaneous profiles shown in Figure 17 (A) were calculated using only three loading harmonics of the FINE ${ }^{\mathrm{TM}} /$ Turbo nonlinear harmonic mode and so do not have features that are as sharp as those shown in Figure 17 (B) [12]. This helps explain why the wake deficit is smaller in the CFD than was measured in the experiment. As mentioned in [12], only three loading harmonics were retained to keep the computational cost reasonable. The focus of the CFD work was the prediction of tone noise from the open rotor propulsion system, and these three harmonics were considered sufficient to capture the frequency content of interest.

The features shown in the dashed lines of Figure 17 (B) show the effect of the aft rotor potential field on the wakes of the forward rotor blades. As the aft rotor passes through the wake, it pushes a higher velocity flow ahead of it while leaving its own wake as a slight deficit behind. This creates local maxima and minima inside of a single blade passage. This distorts the wake causing local increases or decreases in the velocity of approximately $\pm 3.5 \%$ of full scale of the mean at this axial location.

Determining the size and shape of the velocity deficit of the wake can be problematic in this case since the passage of the aft rotor potential field alters the characteristic of the wake and removes some of the features generally used to measure the wake, including a sharp change in the slope of the velocity profile that marks the edge. Other flow features, most notably the front rotor tip vortices, are more amenable to tracking and

9

This material is declared a work of the U.S. Government and is not subject to copyright protection in the United States. Approved for public release; distribution is unlimited. 
measurement. The following section will analyze the tip vortices in greater detail.

\section{EFFECT OF THE AFT ROTOR ON THE FORWARD ROTOR TIP VORTEX}

One of the flow features that has the potential to be affected by the aft rotor and also have a large impact on the radiated acoustics is the forward rotor tip vortex. The tip vortex can be tracked and measured by various means, the simplest of which is finding the location of the point of maximum vorticity within the region of interest. This method could be problematic if the velocity vector maps are not sufficiently dense to provide for reliable vorticity calculations. A preferred method of determining the location of the vortex is the use of the circulation density, $\gamma$, defined as

$$
\gamma(x, \phi)=\int \omega_{z}(x, y, \phi) d y
$$

where $\omega_{z}$ is the out of plane vorticity and $\phi$ is the relative aft rotor phase angle. Note that this definition can be applied in either the $x$ or $y$ directions. The circulation density has a local maximum at the location where the integrated vorticity is the highest, which is the center of the vortex. The center of the vortex can be determined by computing the circulation density in each direction and finding the local maxima. This was accomplished by fitting a $2^{\text {nd }}$ order polynomial to the peak portion of the curve and finding the location of the maximum of the polynomial. This method allowed for a more precise location, rather than relying solely on the resolution of the PIV data for placement, especially since there are only 25 data planes available in the $\mathrm{x}$-direction.

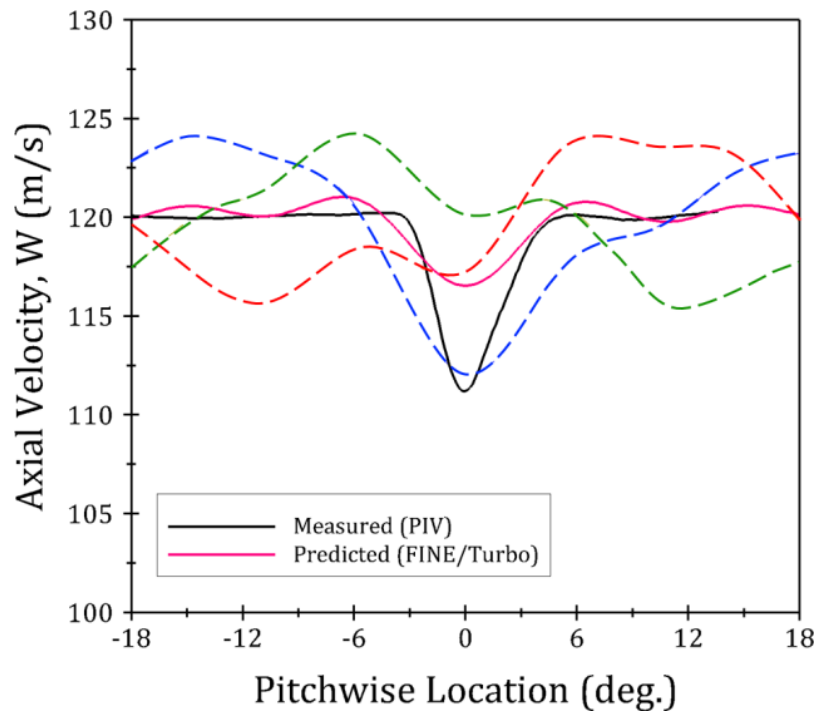

(A) CFD computed instantaneous wakes.
An example is given in Figure 18. At this streamwise location, only 15 data planes are available, and the utility of the curvefitting method can be observed. Care was taken to ensure only one vortex was in the interrogation region during the calculation.

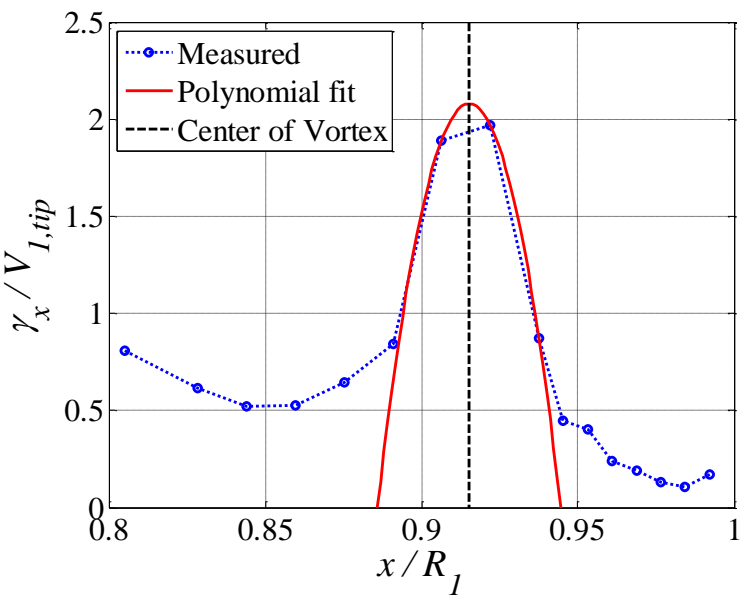

\section{FIGURE 18. EXAMPLE OF VORTEX LOCATION DETERMINATION METHOD.}

After the position of the center of the vortex was determined in the Cartesian PIV coordinate system, the center was rotated into a polar coordinate system with $r_{0}$ and $\theta_{0}$ being the radial and pitchwise locations of the center, respectively. The mean across all aft rotor phase angles was calculated for the center and is denoted by an over bar on each variable.

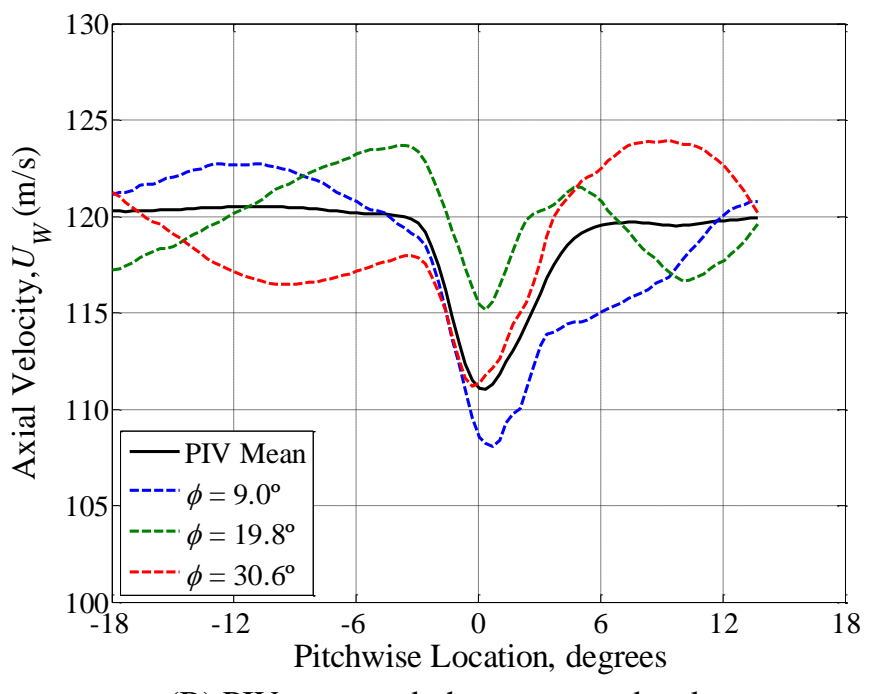

(B) PIV measured phase averaged wakes.

FIGURE 17. AXIAL VELOCITY IN A PLANE 5.70 CM UPSTREAM OF THE AFT ROTOR PITCH CHANGE AXIS (Z/R = -0.4). (A) COMPARISON OF MEASURED TO PREDICTED AXIAL VELOCITY ALONG SAME CONSTANT RADIUS LINE. IMAGE FROM REF. [12]. (B) DASHED LINES ARE AXIAL VELOCITY ALONG CONSTANT RADIUS AT THREE DIFFERENT AFT ROTOR PHASE ANGLES. BLACK LINE IS MEAN WAKE ACROSS ALL PHASE ANGLES.

10

This material is declared a work of the U.S. Government and is not subject to copyright protection in the United States. Approved for public release; distribution is unlimited. 


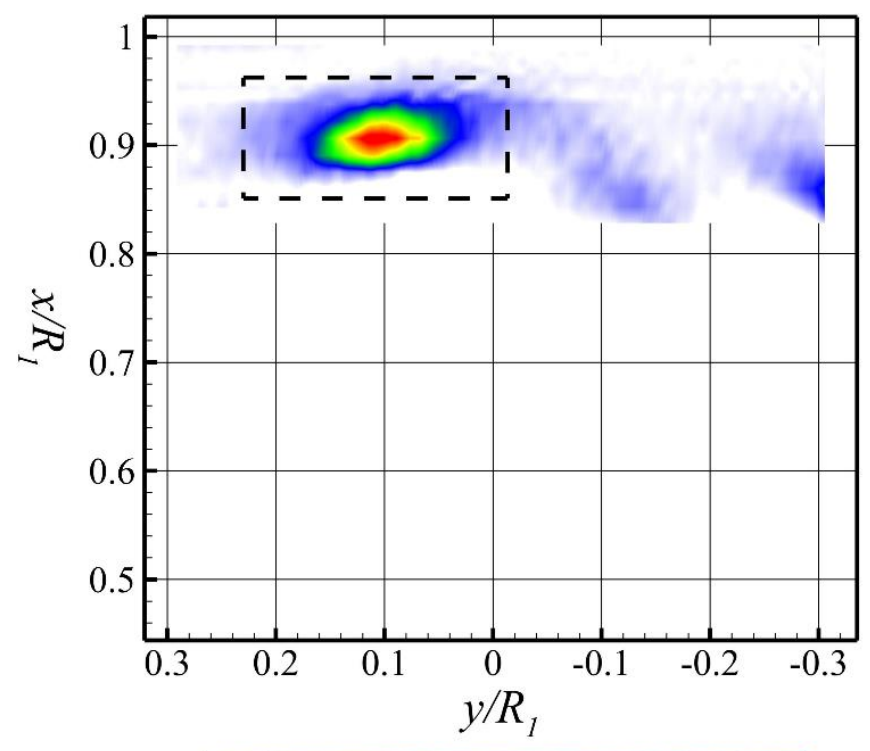

$\begin{array}{lllllllllll}0 & 1 & 2 & 3 & 4 & 5 & 6 & 7 & 8 & 9 & 10\end{array}$ Normalized Axial Vorticity

FIGURE 19. CONTOURS OF AXIAL VORTICITY AT A PLANE Z/R1 = 0.44, OR 5.6 CM (2.25 INCHES) UPSTREAM OF THE AFT ROTOR PITCH CHANGE AXIS. DASHED LINE SHOWS BOUNDING BOX FOR CIRCULATION CALCULATION.

The strength of the vortex can also be determined in a number of ways. The particular method chosen for this analysis was to compute the total circulation strength of the vortex, $\Gamma$, by a surface integral of perpendicular vorticity. A bounding box must be chosen for the integration and was selected to be $0.2 R_{I}$ by 0.1 R1 $(7.1 \mathrm{~cm}$ wide by $3.8 \mathrm{~cm})$ tall, centered on the vortex. Figure 19 shows contours of axial vorticity with the bounding box centered on the vortex. The bounding box is somewhat arbitrary in size and care was taken that only a small portion of the vorticity from the forward rotor wake was a part of the box. Normalized vorticity was calculated from velocity normalized by $V_{l, t i p}$ and length normalized by $R_{l}$.

Figure 20 shows the position and strength for the tip vortex for four different test cases, all with the blades pitched for a takeoff configuration. The four test cases are comprised of two cases at approximately 6450 RPM, denoted as the high RPM test case, and two cases at approximately 5680 RPM, denoted as the low RPM test case. For the low and high RPM cases, there are two forward rotor phase angles, $0^{\circ}$ and approximately $15^{\circ}$, as noted in Table 1.

A careful study of Figure 20 shows that the aft rotor does not have a large effect on the radial position of the forward rotor tip vortex in this particular axial plane. The radial position of the vortex varies within $\pm 0.008 R_{l}$ for the high RPM case and $\pm 0.004 R_{l}$ for the low RPM case. The radial PIV grid spacing near the center of the tip vortex is $5 \mathrm{~mm}(0.2$ inches $)$ per radial grid point, however the polynomial interpolation scheme provided better resolution to this measurement. Because of the small variations of position, it can be concluded that the radial position is not affected by the presence of the aft rotor in this axial plane. However, as the vortex moves closer to the aft rotor, the effect should become more pronounced.

The circumferential, or pitchwise, location of the vortex follows a similar trend as the radial position. While the tangential PIV grid resolution was an order of magnitude higher than the radial, the pitchwise location of the vortex stayed within $\pm 1^{\circ}$ for high RPM and $\pm 0.25^{\circ}$ for the low RPM case. Again, this is little
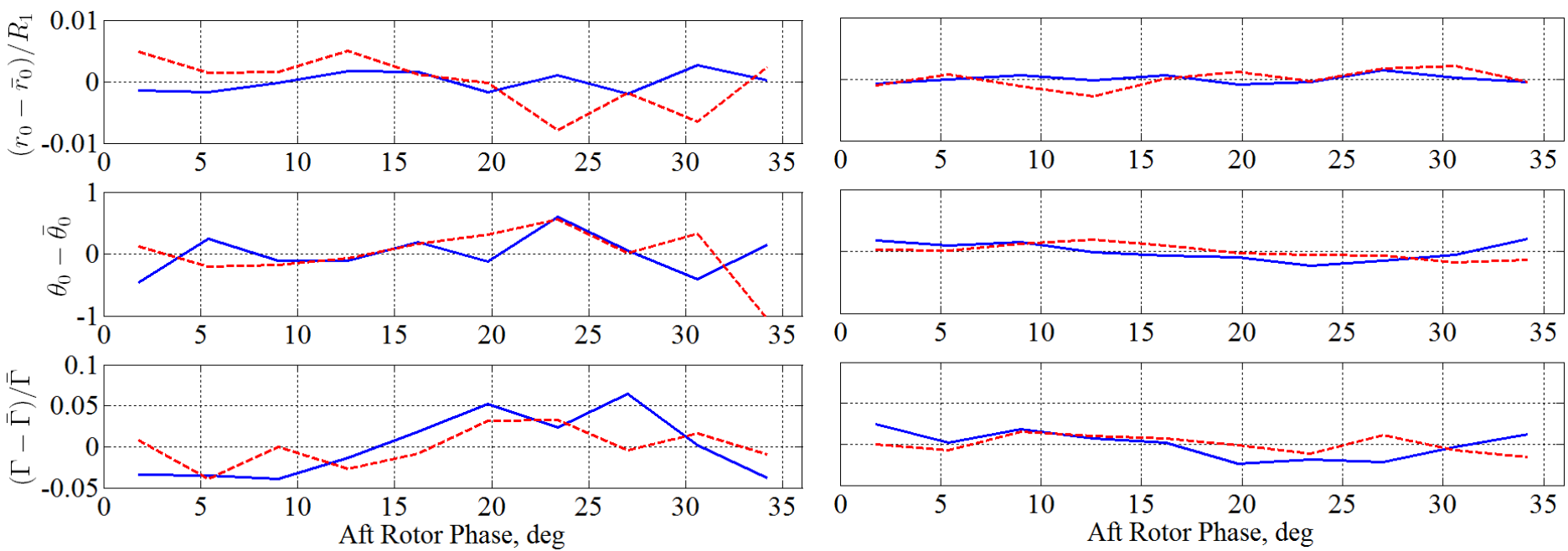

(A) High RPM, Test Cases $1 \& 2$
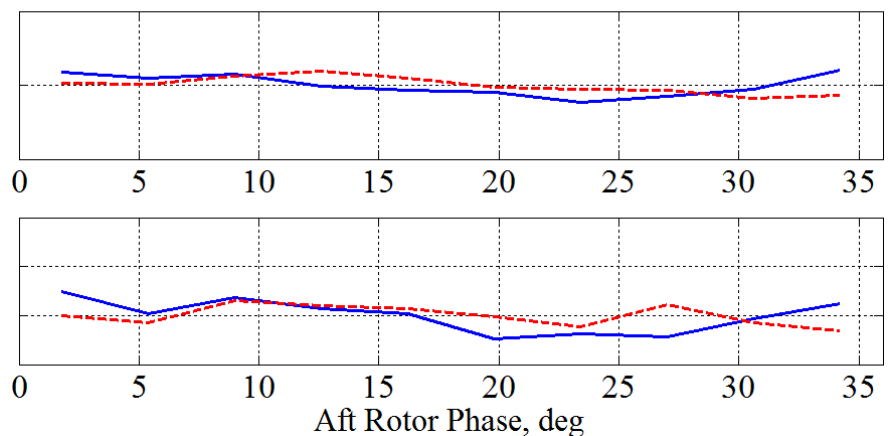

(B) Low RPM, Test Cases 3 \& 4

FIGURE 20. SIZE AND POSITION OF THE FORWARD ROTOR TIP VORTEX FOR (A) HIGH RPM CASE AND (B) LOW RPM CASE VS RELATIVE AFT ROTOR PHASE ANGLE. SOLID BLUE LINES REPRESENT FORWARD ROTOR AT ABSOLUTE PHASE OF $0^{\circ}$ AND DASHED RED LINES REPRESENT FORWARD ROTOR ABSOLUTE PHASE OF APPROXIMATELY $15^{\circ}$.

11

This material is declared a work of the U.S. Government and is not subject to copyright protection in the United States. Approved for public release; distribution is unlimited. 
movement of the tip vortex and it is concluded that the aft rotor has little to no effect on the pitchwise location of the forward rotor tip vortex.

The strength of the vortex varies more than the position as a function of relative aft rotor phase angle. In the high RPM case, the circulation strength is shown to vary from the mean by $\pm 5 \%$ while the low RPM case varies by only $\pm 2.5 \%$. This difference between the high and low RPM cases is to be expected as the high RPM case has much higher blade loading on both rotors with a higher thrust ratio. For the low RPM case, the variation in circulation strength is below the experimental uncertainty and it can be concluded that the aft rotor has little to no effect on the circulation strength of the forward rotor tip vortex.

The high RPM case, however, does show an effect on the strength of the tip vortex. The variation with relative aft rotor phase angle appears to be real and measurable for two distinct test cases. The total variation is approximately $\pm 5 \%$ of the mean circulation strength and changes in a consistent manner over the range of relative phase angles. This suggests a causal effect of the aft rotor on the forward rotor tip vortex. While the change in circulation strength is relatively small, this could have an effect on the radiated acoustics. It is noted that the front rotor tip vortex is indeed cut by the rear rotor blades, which are $0.97 R_{l}$ in radius.

\section{CONCLUSIONS}

The large PIV dataset was successfully phase averaged based upon the relative phase between the forward and aft rotors. The image processing algorithm was able to track the features of the aft rotor blade and determine the position given the geometry of the camera and rig setup. The aft rotor phase averaged data showed the effects of the aft rotor potential field. It was observed that the aft rotor potential field decayed rapidly with upstream distance. As such, it generated relatively weak $(<2 \%)$ oscillations in the flow field at the particular front rotor blade trailing midspan location investigated.

The forward rotor blade wakes were studied in greater detail to determine the effects of the aft rotor. It was found that the instantaneous variations in the blade wake found in the CFD simulations were also present in the experimental aft rotor phase averaged data. The CFD simulations and PIV data were found to be in reasonably good agreement. The potential field of the aft rotor was examined and found to propagate upstream with a functional form somewhat deviating from the expected exponential decay.

The aft rotor was found to have no significant effects on the position of the forward rotor tip vortex for either of the two experimental conditions studied. However, the aft rotor did have a measureable effect on the strength of the forward rotor tip vortex for the high speed case. While the effect was small, of the order of $\pm 5 \%$, it was measureable and found in two separate trials of the same nominal conditions.

For future open rotor PIV testing it is recommended to record a phase reference for both rotors along with the PIV trigger signal. It would also be useful to have a more closely uniform grid spacing in all dimensions.

\section{ACKNOWLEDGMENTS}

The open rotor wind tunnel test campaign was funded by the NASA Environmentally Responsible Aviation (ERA) project, in collaboration with GE Aviation. ERA additionally funded Dr. Slaboch through the NASA Glenn Faculty Fellowship Program (NGFFP). The NASA Advanced Air Transportation Technology project also contributed to the preparation of this report.

\section{REFERENCES}

[1] M. D. Bowles, 2010, The Apollo of Aeronautics, NASA's Aircraft Energy Efficiency Program, SP-2009-574, NASA.

[2] D. E. Van Zante, F. Collier, A. Orton, S. A. Khalid, J. Wojno and T. H. Wood, 2014, "Progress in open rotor propulsors: The FAA/GE/NASA Open Rotor test," The Aeronautical Journal, 118(1208), pp. 1181-1213.

[3] A. Stürmer, C. O. Marquez Gutierrez, E. W. M. Roosenboom, A. Schröder, R. Geisler, D. Pallek, J. Agoc and K.-P. Neitzke, 2012, "Experimental and Numerical Investigation of a Contra Rotating Open-Rotor Flowfield," Journal of Aircraft, 46(6), pp. 1868-1877.

[4] A. Stürmer, 2008, "Unsteady CFD Simulations of ContraRotating Propeller Propulsion Systems, AIAA 20085218," in 44th AIAA/ASME/SAE/ASEE Joint Propulsion Conference \& Exhibit, Hartfort, Connecticut, USA.

[5] R. Boisard, G. Delattre and F. Falissard, 2014, "Computational Fluid Dynamics as a Support to CounterRotating Open-Rotor Wind-Tunnel Test Analysis," Journal of Aircraft, 51(2), pp. 614-628.

[6] R. Schnell, J. Yin, S. Funke and H. Siller, 2012, "Aerodynamic and Basic Acoustic Optimization of a Counter Rotating Open Rotor with Experimental Verification (AIAA 2012-2127)," in 18th AIAA/CEAS Aeroacoustics Conference (33rd AIAA Aeroacoustics Conference), Colorado Springs, Colorado, USA.

[7] O. Uzol, Y.-C. Chow, J. Katz and C. Meneveau, 2002, "Unobstructed particle image velocimetry measurements within an axial turbo-pump using liquid and blades with matched refractive indices," Experiments in Fluids, 33, pp. 909-919.

[8] Y.-C. Chow, O. Uzol, J. Katz and C. Meneveau, 2003, "Experimental Study of the Structure of a Rotor Wake in a Complex Turbomachinery Flow," in 4TH ASME JSME Joint Fluids Engineering Conference, Honolulu, Hawaii, USA.

[9] A. B. Parry and D. G. Crighton, 1989, "Prediction of counter-rotation propeller noise," in 12th Aeroacoustic Conference, San Antonio, Texas, USA.

[10] D. E. Van Zante and M. P. Wernet, 2012, "Tip Vortex and Wake Characteristics of a Counterrotating Open Rotor (TM-2012-217713)," NASA.

This material is declared a work of the U.S. Government and is not subject to copyright protection in the United States. Approved for public release; distribution is unlimited. 
[11] D. B. Stephens, 2014, "Data Summary Report for the Open Rotor Propulsion Rig Equipped with F31/A31 Rotor Blades," NASA/TM-2014-216676.

[12] D. E. Van Zante and E. Envia, 2014, "Prediction of the Aero-Acoustic Performance of Open Rotors (GT201426413)," in Proceedings of ASME Turbo Expo 2014: Turbine Technical Conference and Exposition, Duesseldorf, Germany.

[13] R. T. Johnston and S. Fleeter, 1996, "Time Resolved Variations of an IGV Flow Field in the Presence of a Rotor Potential Field (AIAA 96-2670)," in AIAA, ASME, SAE, and ASEE, Joint Propulsion Conference and Exhibit, Lake Buena Vista, FL, USA.

[14] D. M. Elliott, 2011, "Initial Investigation of the Acoustics of a Counter Rotating Open Rotor Model With Historical Baseline Blades in a Low Speed Wind Tunnel," in 17th AIAA/CEAS Aeroacoustics Conference, Portland, OR, USA.

[15] D. B. Hanson, 1984, "Noise of counter-rotation propellers," in 9th Aeroacoustics Conference, Williamsburg, Virginia, USA.

[16] C. Horváth, 2015, "Beamforming Investigation of Dominant Counter-Rotating Open Rotor Tonal and Broadband Noise Sources," AIAA Journal, 53(6), pp. 1602-1611.

[17] C. Horváth, E. Envia and G. G. Podboy, 2014, "Limitations of Phased Array Beamforming in Open Rotor Noise Source Imaging," AIAA Journal, 52(8), pp. 1810-1817.

[18] D. B. Stephens and H. Vold, 2014, "Order tracking signal processing for open rotor acoustics," Journal of Sound and Vibration, 333, pp. 3818-3830.

[19] R. P. Woodward, 1987, "Noise of a model high speed counterrotation propeller at simulated takeoff/approach conditions (F7/A7) NASA-TM-100206," NASA Lewis Research Center, Cleveland, OH, USA.

This material is declared a work of the U.S. Government and is not subject to copyright protection in the United States. Approved for public release; distribution is unlimited. 